\title{
Effect of pipe-cooling system on thermal- mechanical behaviour of PC box bridge girders at hydration age
}

\author{
Chaojie Song, Gang Zhang ${ }^{*}$, Hao Wen and Yongfei Zhang
}

\author{
*Correspondence: zhangg_2004@ \\ 126.com \\ School of Highway, Chang'an \\ University, Xi'an 710064, Shaanxi, \\ China
}

\begin{abstract}
Prestressed concrete (PC) box bridge girders on the pier top is prone to generate thermal cracks due to large inner-outer temperature difference at hydration age. This paper presents an approach for investigating behaviour of PC box bridge girders at early age of curing. First, based on measured data from a typical PC box bridge girder, an inverse analysis method for adiabatic temperature rise function of concrete hydration heat is proposed using genetic algorithm and thermal analysis. Then, a thermo-hydro-mechanical coupling model is established, using the computer program ANSYS incorporating time-dependent wind speed and ambient temperature, to analyse thermal mechanical behaviour of PC box bridge girders considering pipecooling system. Subsequently, parametric studies are carried out to evaluate influence of cooling time, cooling water flow rate, cooling water temperature and cooling period on temperature and stress of PC box bridge girders during curing. Results from analysis show that the principal tensile stress generated in the vicinity of pipe increases more rapidly during cooling, while the temperature and principal tensile stress can be significantly reduced when cooling is terminated. Increasing cooling time, cooling water flow rate or decreasing cooling water temperature can reduce the highest temperature. However, unreasonable value of these cooling parameters will cause PC box bridge girders cracking due to excessive principal tensile stress around pipe. Both one-stage and two-stage cooling are effective measures to minimize the adverse effects of hydration heat in PC box bridge girders.
\end{abstract}

Keywords: Prestressed concrete box bridge girder, Hydration heat, Finite element method, Pipe-cooling system, Thermal-mechanical behaviour, Parametric studies

\section{Introduction}

In the mass concrete structures, large amount of heat generated by cement hydration is accumulated due to lower thermal conductivity of concrete. The interior of concrete under high temperature tends to expand, whereas surface of concrete close to ambient temperature tends to shrink, resulting in tensile stress on surface of PC box bridge girders. Cracks will occur on the concrete surface when the tensile stress exceeds the tensile strength (Zhu 2013). However, cracks are not permitted in PC box bridge girders because cracks have adverse effects on safety, integrity and durability of structure

(c) The Author(s). 2020 Open Access This article is licensed under a Creative Commons Attribution 4.0 International License, which permits use, sharing, adaptation, distribution and reproduction in any medium or format, as long as you give appropriate credit to the original author(s) and the source, provide a link to the Creative Commons licence, and indicate if changes were made. The images or other third party material in this article are included in the article's Creative Commons licence, unless indicated otherwise in a credit line to the material. If material is not included in the article's Creative Commons licence and your intended use is not permitted by statutory regulation or exceeds the permitted use, you will need to obtain permission directly from the copyright holder. To view a copy of this licence, visit http://creativecommons.org/licenses/by/4.0/. 
(Schackow et al. 2016; Zhang et al. 2017). Hence, it is necessary to investigate development of temperature and stress in PC box bridge girders during curing, and also propose measures to prevent cracking. Nowadays, many technologies have been proposed to prevent thermal cracking caused by cement hydration heat, such as pre-cooling, pipecooling, surface thermal blankets and low heat cement (Kim et al. 2015; Kodur et al. 2016; Schackow et al. 2016). Cooling by flow water through an embedded pipe is a common artificial temperature control measure on concrete dams, foundations and other mass concrete structures (Chen et al. 2011; Liu et al. 2015; Zuo et al. 2014).

In the past decades, numerous studies of cement hydration heat effects on mass concrete structures have been conducted (Davie et al. 2010; Kodur et al. 2016; SabbaghYazdi et al. 2013; Singh and Rai 2018; Tahersima and Tikalsky 2017; Wang et al. 2015; Yang et al. 2012; Zhu et al. 2013). However, little research on PC box girders is reported due to structural complexity of PC box bridge girders on the pier top, and large number of prestressing strands within body of girders (Zhang et al. 2017). Many methods have been proposed, such as pseudo three-dimensional finite element methods (Myers et al. 2009), thermal-fluid coupling method (Liu et al. 2013), p-version finite element method (Zuo et al. 2015) and composite-element method (Chen et al. 2011) to obtain more accurate calculation method for pipe-cooling system. In the thermal-fluid coupling method, the position and size of pipe are accurately modelled according to the design, which can accurately simulate the convection heat transfer between cooling water and concrete, and temperature rise of cooling water along pipe due to heat generated by cement hydration (Cheng et al. 2016; Liu et al. 2013; Liu et al. 2015). In addition, the cooling effect is closely related to the cooling parameters when pipe-cooling is used in concrete structure. The determination of cooling parameters, namely cooling water temperature, cooling water flow rate, cooling time and cooling period is critical for temperature control of PC box bridge girders on the pier top (Cheng et al. 2016).

Furthermore, thermal properties of concrete are critical in simulation of temperature field in mass concrete structure (Ding and Chen 2013; Kim et al. 2015). Previously, thermal properties are taken according to laboratory tests or empirically for highstrength concrete materials commonly used in long-span bridges. However, since thermal parameters are affected by boundary conditions, ambient environment and mix proportion, relying on empirical values or laboratory test will inevitably have a great influence on calculation accuracy of temperature field (Wang et al. 2015). Therefore, the method to determine thermal properties of materials needs to be discussed.

In this paper, an inverse analysis method is developed to obtain unknown parameters of adiabatic temperature rise function, and then a thermo-hydro-mechanical model is established, incorporating wind speed, ambient temperature and pipe-cooling system, to trace progression of temperature and stress in PC box bridge girders on the pier top at hydration age. Finally, this model is applied to evaluate effect of critical factors of pipe-cooling system on thermal mechanical behaviour of PC box bridge girders at early age. 


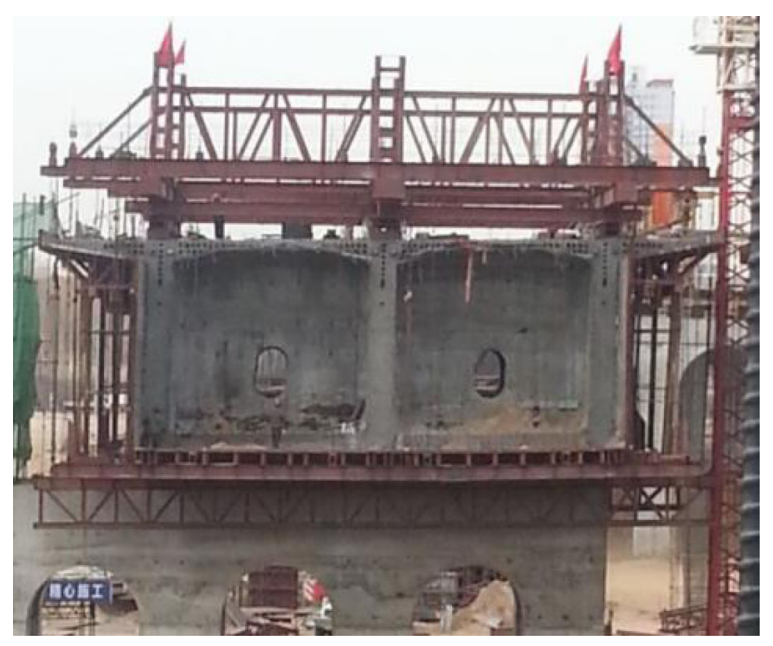

The PC box bridge girder on the pier top

Fig. 1 The PC box bridge girder on the pier top

\section{Selection of PC box bridge girder}

\subsection{Details}

A typical massive concrete structure on the pier top of PC box bridge girder, comprising a double chamber, as shown in Fig. 1, is selected to carry out hydration heat analysis. The width of box girder section is $20 \mathrm{~m}$, and the height is $7 \mathrm{~m}$. Three-dimensional (longitudinal, transversal and vertical) prestress are installed in the PC box bridge girder to improve flexural, shear and local stress distribution. Details of the PC box bridge girder are shown in Fig. 2. The PC box bridge girder on the pier top is divided into two layers for pouring. The bottom flange and part of the web (below $3.2 \mathrm{~m}$ ) are poured first, and then the remaining part is poured after $8 \mathrm{~h}$.

\subsection{Material properties}

The properties of constituent materials play a crucial role in thermo-mechanical analysis of PC box bridge girders during curing (Kim et al. 2015). Thus, relevant thermal and mechanical properties of concrete are incorporated into the finite element model. The PC box bridge girder is made of concrete with cube strength of $55 \mathrm{MPa}$ and the mix proportion is listed in Table 1. Thermal properties including specific heat, density, thermal conductivity and expansion coefficient are tabulated in Table 2. Values of specific heat and thermal conductivity are given in Table 2 as a function of temperature, and linear interpolation method is used for the intermediate temperature (Zhu 2013). Concrete prisms were fabricated during construction of the PC box bridge girder to test elastic modulus and tensile strength of concrete at its early hydration age. Representative test data of elastic modulus and tensile strength are summarized in Table 3.

\subsection{Instrumentation}

The instrument arranged on the PC box bridge girder includes temperature sensors to measure cross-sectional temperature and vibration wire strain sensors to 


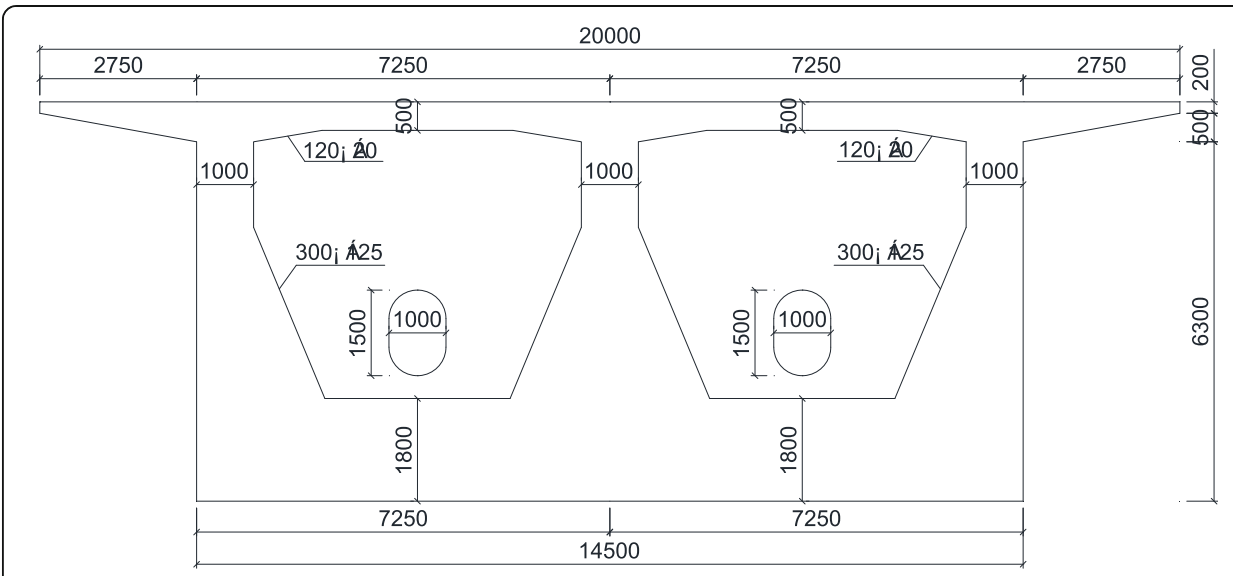

Fig. 2 Details of the PC box bridge girder (units: $\mathrm{mm}$ )

measure strain. The temperature measurement ranges from $-10^{\circ} \mathrm{C}$ to $80{ }^{\circ} \mathrm{C}$ and the sensitivity is $0.1{ }^{\circ} \mathrm{C}$. The strain measurement ranges from $-1500 \mu \varepsilon$ to1500 $\mu \varepsilon$ and the sensitivity is $1 \mu \varepsilon$. Due to symmetry of structure and boundary conditions of the PC box bridge girder, the temperature and stress distribution are also symmetrical. Therefore, only half of the structure is equipped with temperature and stress measuring points. Details of instrument layout are shown in Fig. 3, in which $\mathrm{T}$ and $\mathrm{G}$ represent testing points of temperature and stress, respectively.

\subsection{Ambient conditions}

The ambient temperature and wind speed have significant effect on the convection heat transfer between PC box bridge girders and ambient environment (Zhang et al. 2017). The difference between ambient temperature and surface temperature of PC box bridge girders is a prerequisite for convection heat transfer. In addition, the value of convection heat transfer coefficient is closely related to wind speed. According to the measured data in construction site, the ambient temperature and wind speed used in thermal analysis of the box girder at hydration age are shown in Fig. 4.

\section{Analysis method}

Based on test data of a typical PC box bridge girder, a numerical analysis method is developed using the computer program ANSYS to trace behaviour of PC box bridge girders during hydration age. A full description for this approach is provided in the following subsections.

\subsection{General approach}

The proposed analysis method for investigating influence of pipe-cooling system on thermal-mechanical behaviour of PC box bridge girders during curing comprises of four steps. In the first step, genetic algorithm and thermal analysis method is used to

Table 1 Mix proportion of concrete

\begin{tabular}{lccccccc}
\hline Constituent & Portland cement & Water & Sand & Gravel & Fly ash & Mineral powder & Water reducer \\
\hline Mix proportion $(\mathrm{kg})$ & 400 & 148 & 653 & 1161 & 55 & 25 & 5.76 \\
\hline
\end{tabular}


Table 2 Thermal properties of concrete

\begin{tabular}{|c|c|c|c|c|c|c|c|c|}
\hline \multirow[t]{2}{*}{ Parameter } & \multicolumn{3}{|c|}{ Specific heat $\left(\mathrm{kJ} /\left(\mathrm{kg} \cdot{ }^{\circ} \mathrm{C}\right)\right)$} & \multirow{2}{*}{ Density $\left(\mathrm{kg} / \mathrm{m}^{3}\right)$} & \multirow{2}{*}{$\begin{array}{l}\text { Expansion coefficient } \\
/\end{array}$} & \multicolumn{3}{|c|}{ Thermal conductivity $\left(\mathrm{kJ} /\left(\mathrm{m} \cdot \mathrm{h} \cdot{ }^{\circ} \mathrm{C}\right)\right.$} \\
\hline & $15^{\circ} \mathrm{C}$ & $43^{\circ} \mathrm{C}$ & $71^{\circ} \mathrm{C}$ & & & $15^{\circ} \mathrm{C}$ & $43^{\circ} \mathrm{C}$ & $71^{\circ} \mathrm{C}$ \\
\hline Value & 0.86 & 0.96 & 1.12 & 2448 & $10^{-5}$ & 7.19 & 7.20 & 7.22 \\
\hline
\end{tabular}

obtain adiabatic temperature rise function of concrete from measured temperature of the PC box bridge girder. In the second step, the adiabatic temperature rise function are provided as input data into ANSYS, and a thermo-hydro-mechanical model is established incorporating wind speed, ambient temperature and pipe-cooling system. In the third step, the temperature and stress of the PC box bridge girder with or without pipe-cooling system are compared to reveal the influence of pipe-cooling system on thermal-structural behaviour of PC box bridge girders at hydration age. In the last step, effects of different parameters, namely cooling time, cooling water flow rate, cooling water temperature and cooling period, on behaviour of PC box bridge girders at early age is evaluated by comparing progression of temperature and stress, and the basic design principles applicable to pipe-cooling system are determined. Figure 5 illustrates the flow chart associated with the proposed procedure.

\subsection{Adiabatic temperature rise function}

The adiabatic temperature rise function of concrete hydration heat adopts the compound exponential expression (Zhu 2013), which can be expressed as follows:

$$
Q(\tau)=Q_{\infty}\left(1-e^{-a \tau^{b}}\right)
$$

Where $\tau$ is the concrete age, $Q(\tau)$ is hydration heat per unit weight cement, $Q_{\infty}$ is the maximum hydration heat per unit weight cement, $\mathrm{a}$ and $\mathrm{b}$ are unknown constants. In the thermal analysis, the adiabatic temperature rise is converted into heat generation rate and then applied to PC box bridge girders as a body load. The heat generation rate is written as following expression

$$
\frac{\mathrm{d} Q(\tau)}{d \tau}=\mathrm{Q}_{\infty} a \mathrm{~b} \tau^{b-1} e^{-a \tau^{b}}
$$

In the thermal analysis, adiabatic temperature rise of concrete determines the simulation accuracy of temperature field (Yang et al. 2012). Unknown parameters of adiabatic temperature rise function are deduced from measured temperature using inverse analysis method. At present, there are many inverse analysis methods, such as simplex method, complex method, least square method and genetic algorithm (Ding and Chen 2013). In this paper, the MATLAB genetic algorithm toolbox is used to realize the application of genetic algorithm in calculating adiabatic temperature rise function, and data exchange is realized between the MATLAB genetic algorithm toolbox and the ANSYS thermal analysis module. The hydration heat temperature field of PC box bridge girders is calculated

Table 3 Elastic modulus and tensile strength of concrete

\begin{tabular}{llllllll}
\hline Time $(\mathrm{h})$ & 48 & 96 & 144 & 192 & 240 & 288 & 336 \\
Elastic modulus (GPa) & 13.2 & 18.5 & 21.7 & 23.9 & 25.7 & 27.1 & 28.3 \\
Tensile strength (MPa) & 1.51 & 1.81 & 1.97 & 2.08 & 2.16 & 2.23 & 2.28 \\
\hline
\end{tabular}




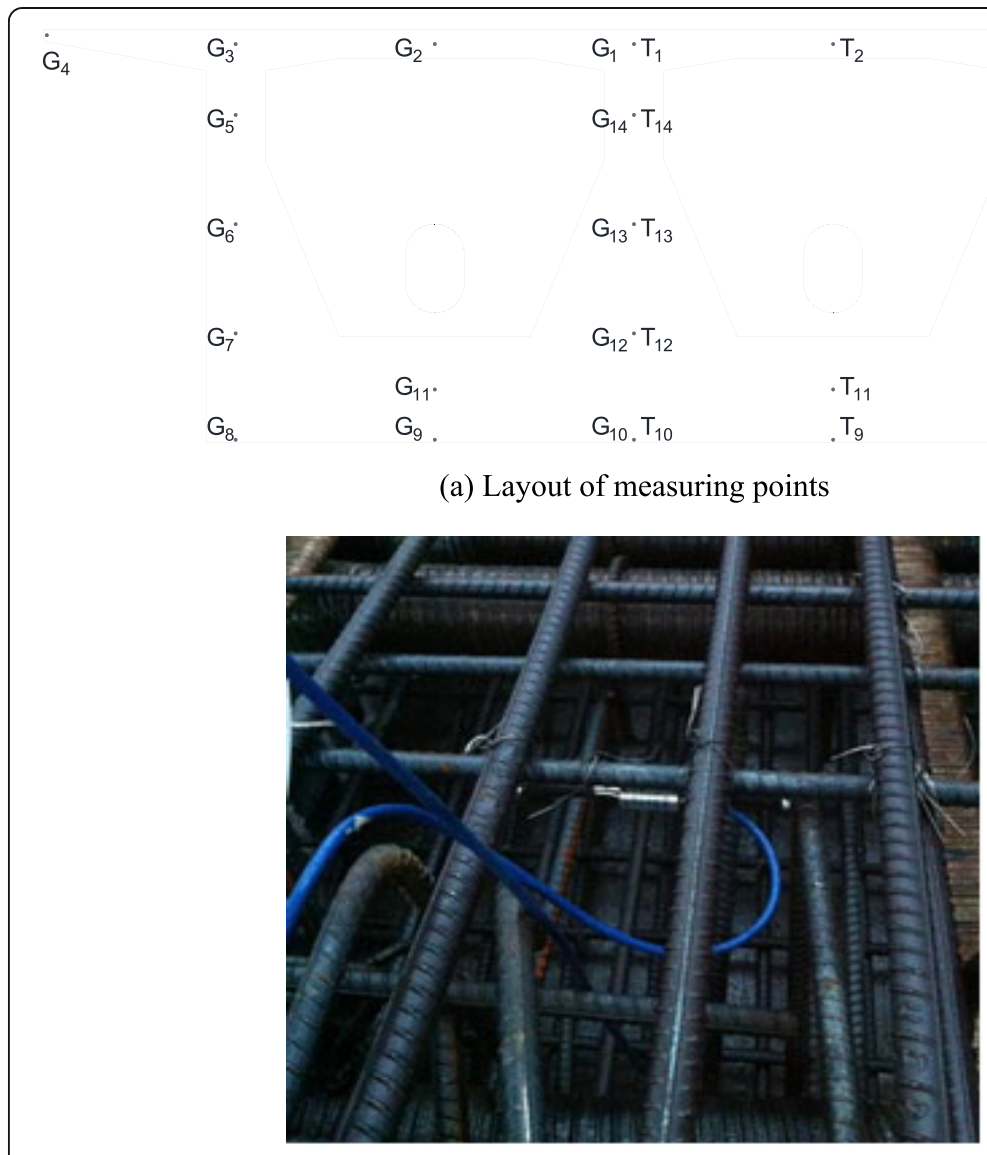

(b) Setup of instrument

Fig. 3 Instrument layout

Fig. 3 Instrument layout

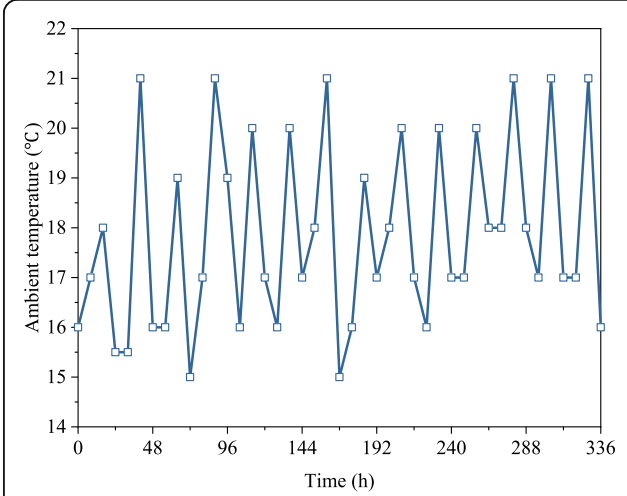

(a) Ambient temperature

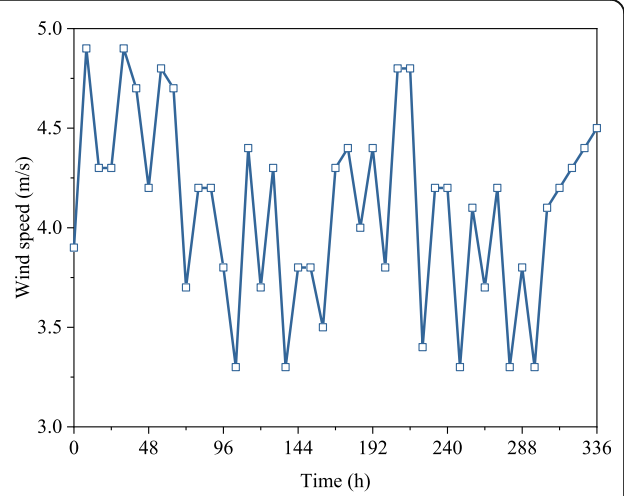

(b) Wind speed

Fig. 4 Ambient conditions

Fig. 4 Ambient conditions 


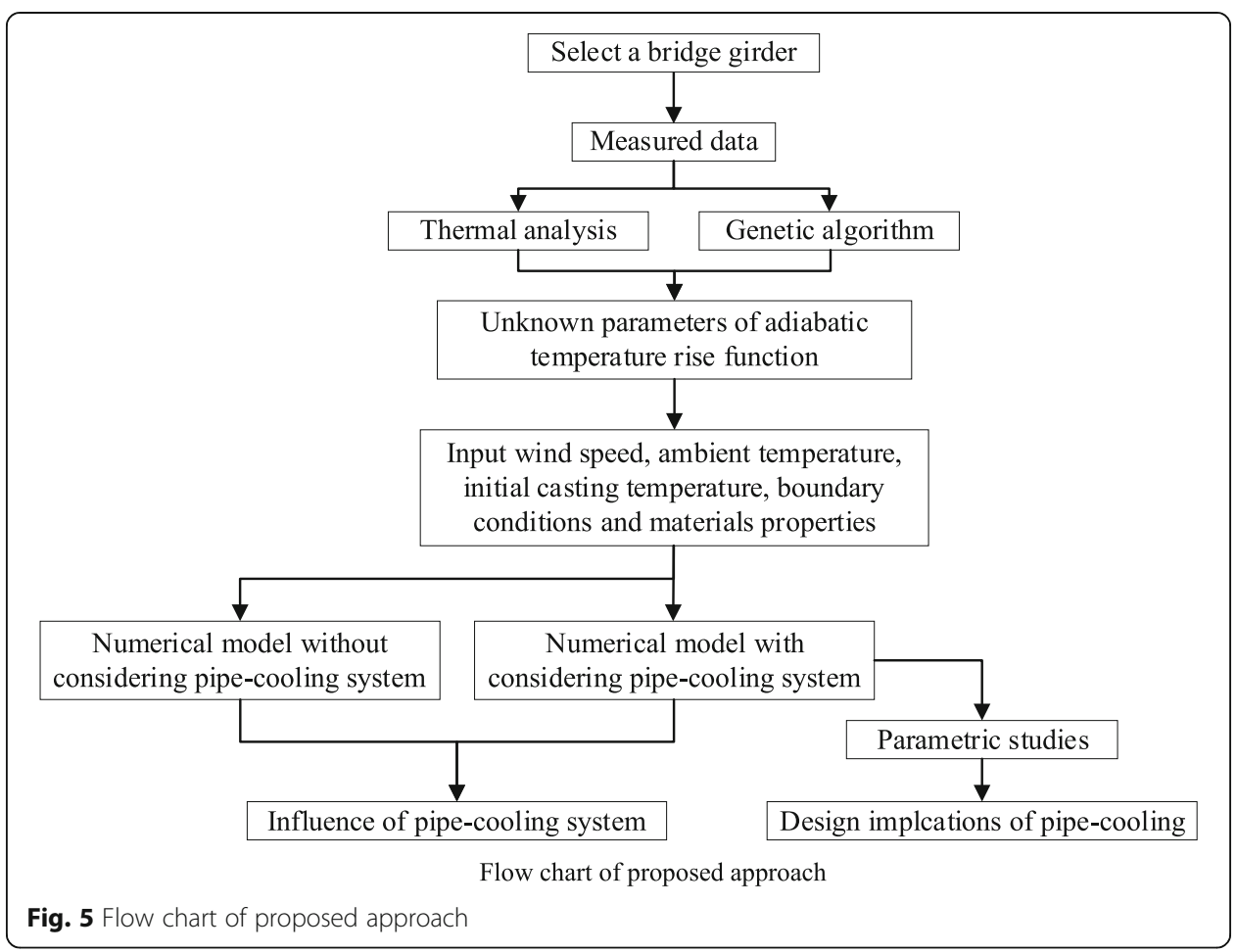

by ANSYS, and the unknown parameters are optimized based on MATLAB genetic algorithm toolbox to find optimal solution of the objective function.

The objective function is listed as follows:

$$
\min \sum_{i=1}^{n}\left[T_{p}\left(x_{i}, y_{i}, z_{i}, t\right)-T_{m}\left(x_{i}, y_{i}, z_{i}, t\right)\right]^{2}
$$

Where $T_{p}\left(x_{i}, y_{i}, z_{i}, t\right)$ is the predicted temperature of point $\left(x_{i}, y_{i}, z_{i}\right)$ at time $t$ and $T_{m}\left(x_{i}\right.$, $\left.y_{i}, z_{i}, t\right)$ is the measured temperature of point $\left(x_{i}, y_{i}, z_{i}\right)$ at time $t$. The evolution of unknown parameters in adiabatic temperature rise function is shown in Fig. 6. Through multiple generations of genetic variation, the unknown parameters $\mathrm{Q}_{\infty}$, $\mathrm{a}$ and $\mathrm{b}$ of adiabatic temperature rise function are $316 \mathrm{~kJ} / \mathrm{kg}, 0.38$ and 0.75 , respectively.

\subsection{Pipe-cooling system}

Due to the complex structure of the PC box bridge girder on the pier top, the additional cooling pipe is easy to cause structural damage and has adverse effect on durability. Therefore, three-dimensional prestressed ducts are generally used as cooling pipe in PC box bridge girders. The layout of cooling pipe is shown in Fig. 7, and the arrow in figure is the direction of water flow.

The determination of cooling parameters, namely cooling water temperature, flow rate and cooling time, is a crucial problem for pipe cooling of PC box bridge girders on the pier top. Similar to the algorithm in Section 3.2, the stress of PC box bridge girders is calculated using ANSYS, and the cooling parameters are optimized using MATLAB 


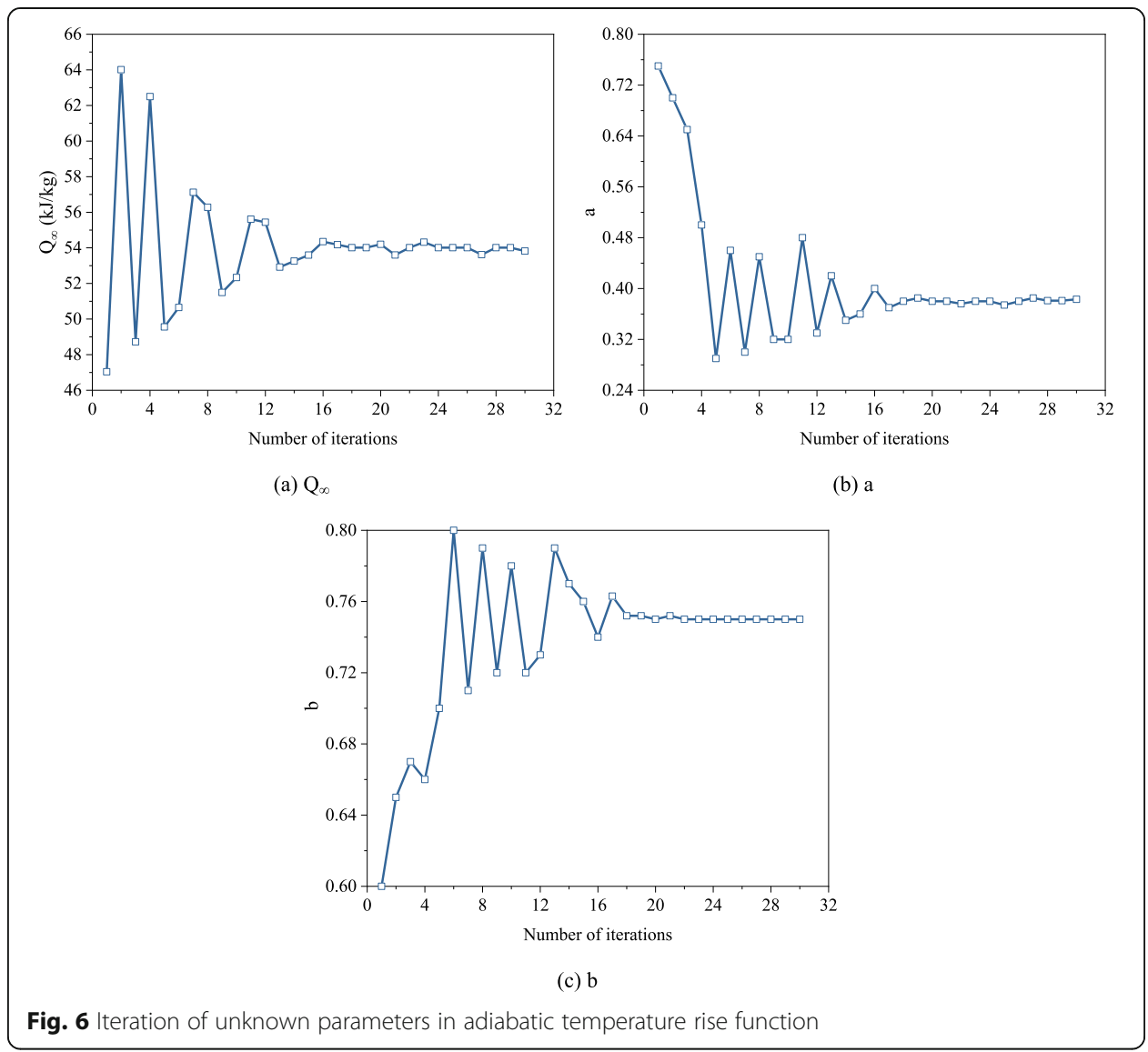

Fig. 6 Iteration of unknown parameters in adiabatic temperature rise function

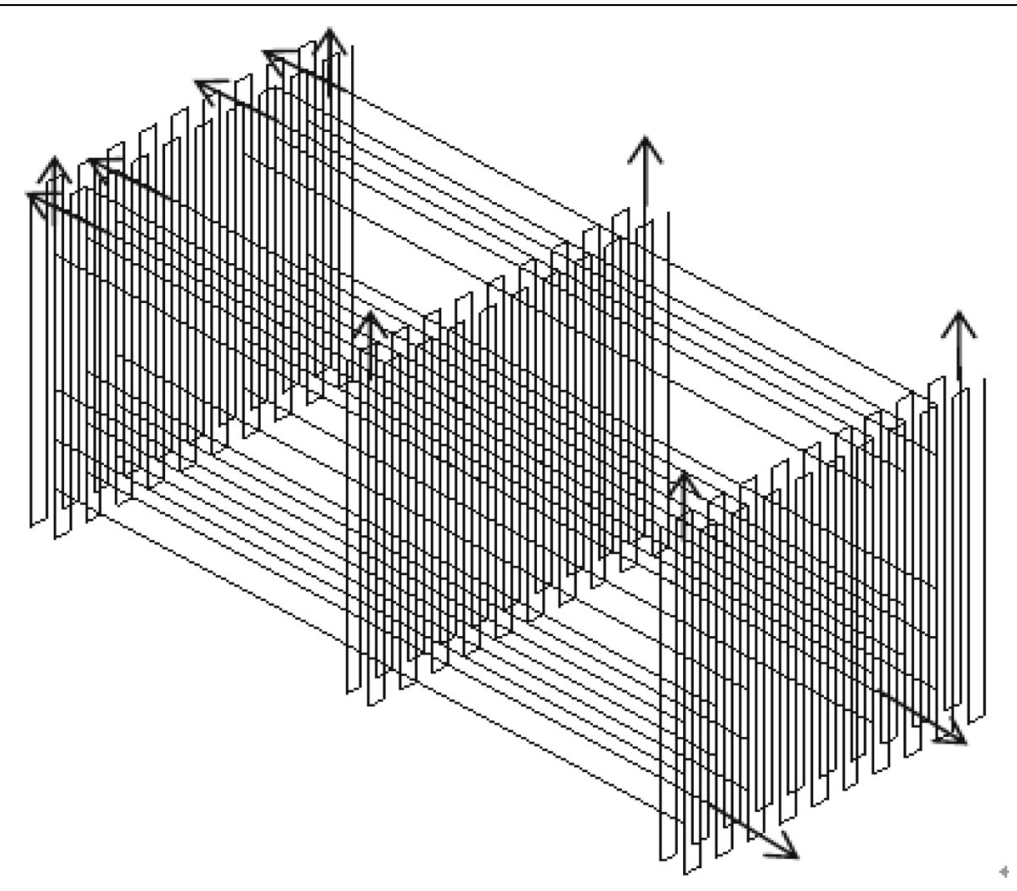

Layout of cooling pipe

Fig. 7 Layout of cooling pipe 
genetic algorithm toolbox to seek the optimal solution of the objective function. The objective function is expressed as follows:

$$
\left\{\begin{array}{l}
\min K_{1} t \\
\sigma_{\mathrm{t}}<[\sigma]_{t} / K \\
0 \leq \nu \leq 3 \\
0 \leq t \leq 14 \\
8 \leq T_{w} \leq 18
\end{array}\right.
$$

Where $K_{1}$ is unit price of pipe cooling system; $t$ is cooling time; $\sigma_{t}$ is the maximum tensile stress; $[\sigma]_{t}$ is the tensile strength; $\mathrm{K}$ is safety factor, taken as $1.15 ; v$ is cooling water flow rate and $\mathrm{T}_{\mathrm{w}}$ is cooling water temperature.

The cooling time is taken as optimization objective, and the maximum tensile stress does not exceed the tensile strength as constraint condition. The results show that the optimal solutions are $15^{\circ} \mathrm{C}, 0.21 \mathrm{~m} / \mathrm{s}$ and $48 \mathrm{~h}$, respectively within a given range of cooling water temperature, cooling time and cooling water flow rate.

\subsection{Numerical model}

Different element types available in ANSYS are used to discretize the PC box bridge girder for thermo-hydro-mechanical analysis, as shown in Fig. 8. The first step is to conduct fluidsolid coupling heat transfer analysis. Subsequently, the temperature distribution, generated from thermal analysis, is enforced on the structural model as nodal load to simulate the thermal effect of PC box bridge girders at its early hydration age (Song et al. 2020).

In the thermal analysis, the PC box bridge girder is discretized with SOLID70 element and pipe-cooling system is simulated using FLUID116 and SURF152 element (ANSYS 2018). SOLID70, 8-node thermal solid with linear shape functions and reduced integration, has 3-D thermal conduction capability with a single temperature degree of freedom at each node. This element is applicable to perform a transient thermal analysis. FLUID116 is a 3-D element with the ability to conduct heat and transmit fluid between its two primary nodes and each node has temperature degree of freedom only. Heat transfer from cooling water to surface of PC box bridge girders through

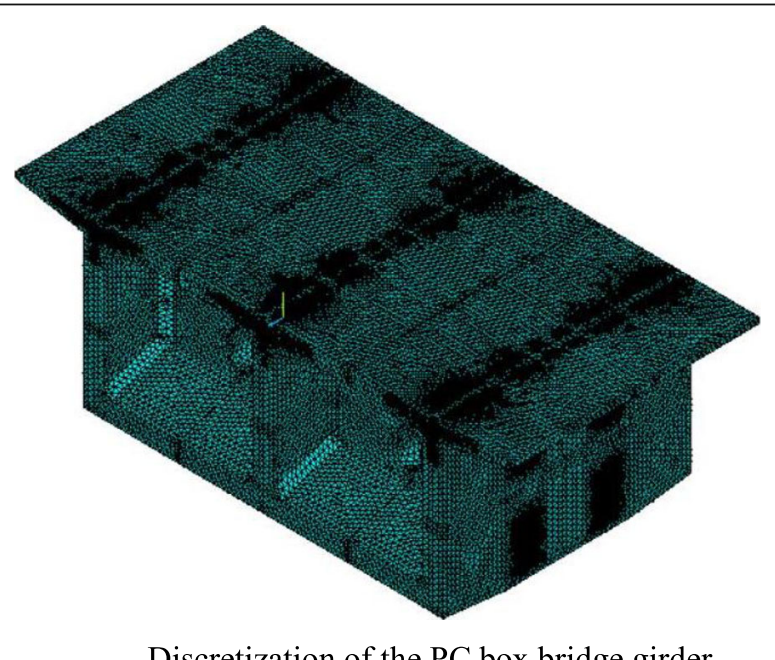

Discretization of the PC box bridge girder

Fig. 8 Discretization of the PC box bridge girder 
conduction can be accounted for SURF152 element. SURF152 is a surface effect element that can be overlaid onto surface of any $3 \mathrm{D}$ thermal element for thermal analysis.

The structural model is established by transforming the SOLID70 into SOLID65 element (ANSYS 2018). SOLID65, 8-node reinforced concrete solid with linear shape functions and reduced integration, has three degrees of freedom at each node (translations in the $\mathrm{x}, \mathrm{y}$, and $\mathrm{z}$ directions). This element, a 3-D modelling of solids, is capable of simulating cracking in tension, crushing in compression and plastic deformation used for nonlinear material properties in concrete.

The birth and death capability of elements is used to simulate layer pouring of PC box bridge girders. The initial temperature of concrete at all nodes is set to be the casting temperature $\left(18^{\circ} \mathrm{C}\right)$, and the hydration heat of concrete is applied to PC box bridge girders with heat generation rate as a body load, as described in Section 3.2. Timedependent ambient temperature and convection heat transfer coefficient are provided as input data into ANSYS every $8 \mathrm{~h}$. The convection heat transfer coefficient of outer surface in PC box bridge girders is significantly affected by wind speed. Therefore, considering effects of wind speed, formwork and thermal blankets, time-dependent convection heat transfer coefficient of outer surface in the PC box bridge girder is calculated according to Zhu (2013), as shown in Fig. 9. There is an assumption that wind speed on all outer surface of the PC box bridge girder is uniform. The convection heat transfer coefficient of inner surface is taken as $16.2 \mathrm{~kJ} / \mathrm{m} \cdot \mathrm{h} \cdot{ }^{\circ} \mathrm{C}$ take into account formwork and thermal blankets.

\section{Results and discussion}

The reliability of developed numerical analysis method is verified by comparing the calculated results with the measured data from an actual PC box bridge girder. The proposed model is used to track progression of temperature and stress in PC box bridge

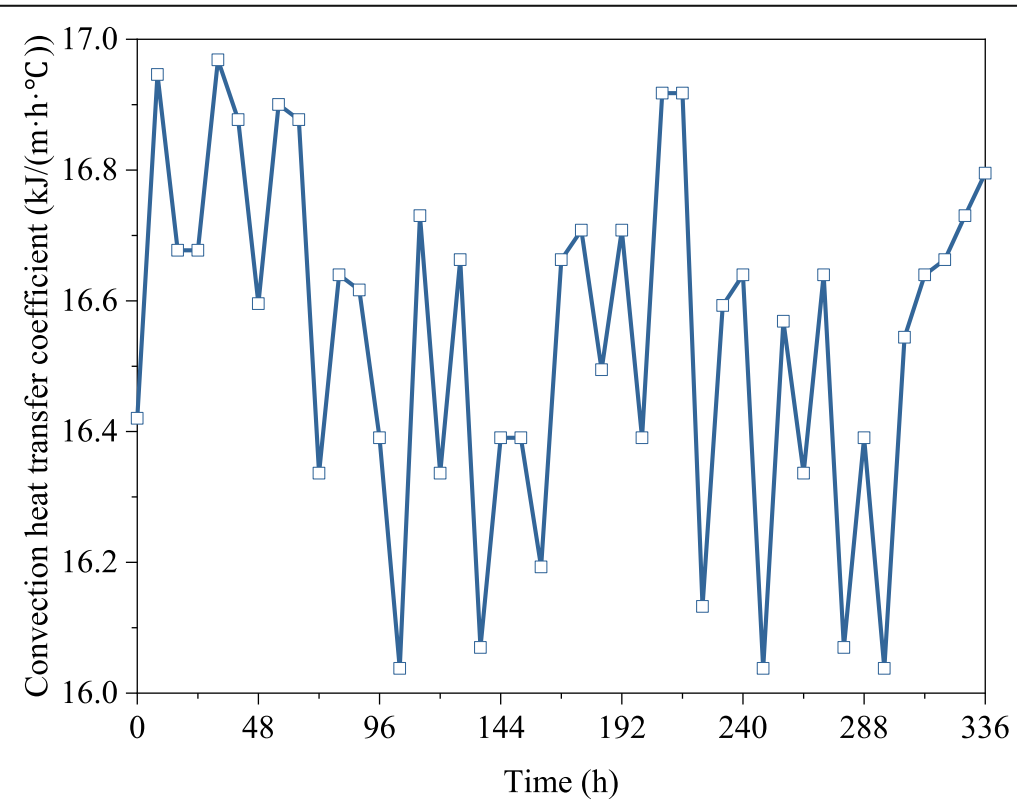

Time-dependent convection heat transfer coefficient

Fig. 9 Time-dependent convection heat transfer coefficient 


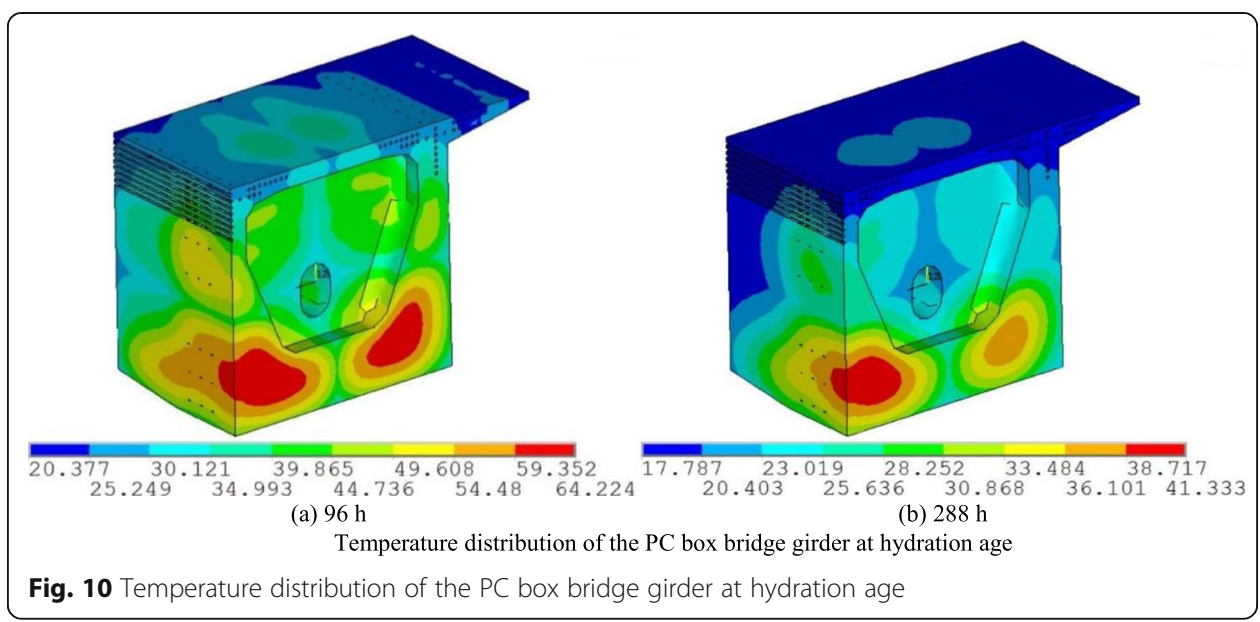

girders during curing, and effect of pipe-cooling system on thermal-structural behaviour of PC box bridge girders are quantified.

\subsection{Thermal analysis}

Figure 10 shows a three-dimensional temperature distribution of the PC box bridge girder without pipe-cooling system at hydration age. The temperature distribution has obvious layering phenomenon due to the fact that the PC box bridge girder on the pier top is divided into two layers for pouring. The temperature at junction of bottom flange, web and diaphragm is much higher than the temperature at other locations due to accumulation of cement hydration heat. The concrete at junction of top flange and web has less heat accumulation due to large number of prestressed ducts in top flange. The contact between prestressed pipe and air accelerates loss of heat, resulting in a lower temperature of top flange.

Figure 11 shows the comparison between predicted and measured temperature in the PC box bridge girder without pipe-cooling system at representative measuring points T12 and T14, which are located in the centre of bottom and top layer, respectively. It can be seen that the predicted hydration heat temperatures agree well with the measured data, indicating that the finite element model established in this paper is capable
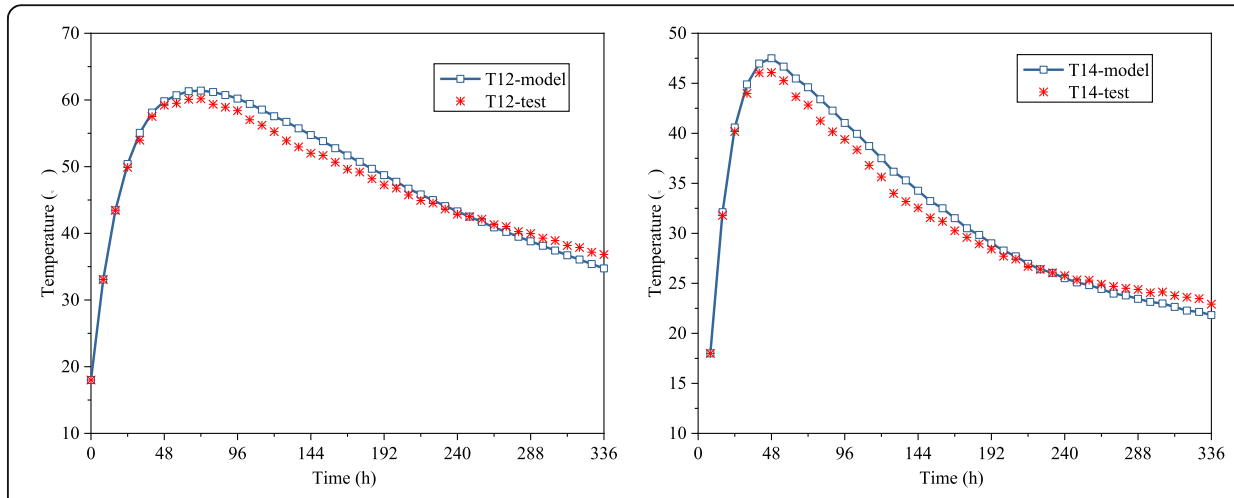

Fig. 11 Comparison between the predicted and measured temperature 
of predicting the temperature distribution of PC box bridge girders on the pier top. The temperature progression of the PC box bridge girder during curing can be grouped into four stages, namely Stage 1, Stage 2, Stage 3 and Stage 4. In Stage 1 (about 32 h), temperature rises rapidly due to the fact that cement hydration generates large amount of heat. In Stage 2 (between $32 \mathrm{~h}$ and $64 \mathrm{~h}$ ), temperature increases slowly mainly due to heat generated by cement hydration gradually decreases. In Stage 3 (between $64 \mathrm{~h}$ and $192 \mathrm{~h}$ ), temperature starts to decrease resulting from cement hydration is further reduced so that heat generation rate is less than the heat transfer with ambient environment. In Stage 4 (after $192 \mathrm{~h}$ ), temperature decreases with much slowly pace due to poor heat transfer caused by lower thermal gradient.

Figure 12 shows an evolution of the highest, lowest temperature and temperature difference in the PC box bridge girder. For the PC box bridge girder without pipe-cooling system, the peak value of highest temperature is $67^{\circ} \mathrm{C}$, which occurs at $64 \mathrm{~h}$. The lowest temperature presents slight fluctuation due to influence of ambient temperature. The maximum temperature difference in the $\mathrm{PC}$ box bridge girder is $31^{\circ} \mathrm{C}$, and its occurrence time is $72 \mathrm{~h}$. When pipe-cooling is used for the PC box bridge girder, the lowest temperature remain unchanged due to pipe-cooling has no influence on surface temperature. The peak value of the highest temperature can be reduced by about $7{ }^{\circ} \mathrm{C}$ and the maximum temperature difference also decreases due to lower highest temperature. The maximum temperature difference reaches the peak value of $24^{\circ} \mathrm{C}$ at $48 \mathrm{~h}$.

\subsection{Structural analysis}

Figure 13 shows the comparison between predicted and measured stress along longitudinal direction at representative measuring points G9 and G14, which are located in the surface and centre of the PC box bridge girder without pipe-cooling system, respectively. It can be seen that the predicted stress shows a good agreement with the measured data. The progression of stress in Fig. 13 is similar to the temperature progression in Fig. 11, except that time corresponding to each stage is different. The four stages of stress evolution are 0 to $56 \mathrm{~h}, 56$ to $120 \mathrm{~h}, 120$ to $240 \mathrm{~h}$ and 240 to $336 \mathrm{~h}$, respectively.

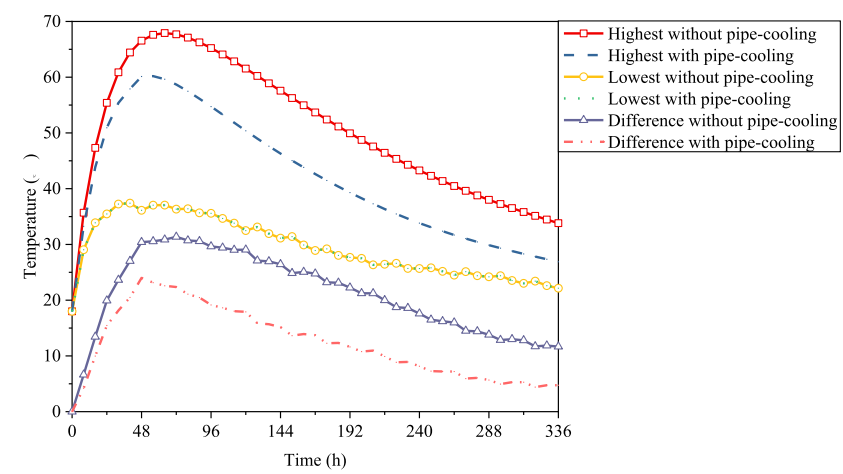

Comparison of maximum, minimum temperature and temperature difference in the PC box bridge girder with or without pipe-cooling system

Fig. 12 Comparison of maximum, minimum temperature and temperature difference in the PC box bridge girder with or without pipe-cooling system 


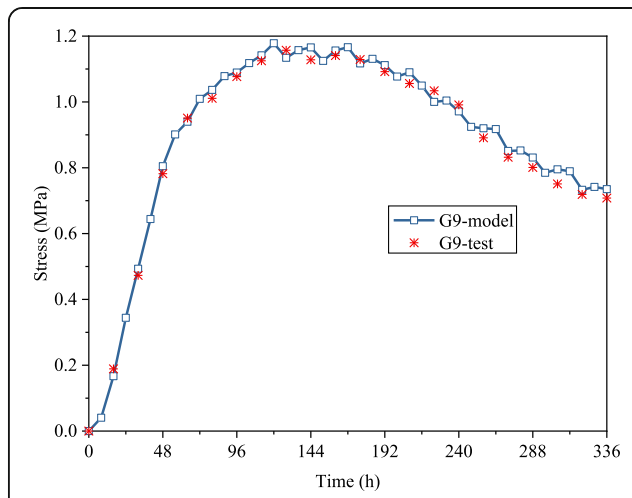

(a) G9

Comparison between the predicted and measured stress along $\mathrm{X}$-axi

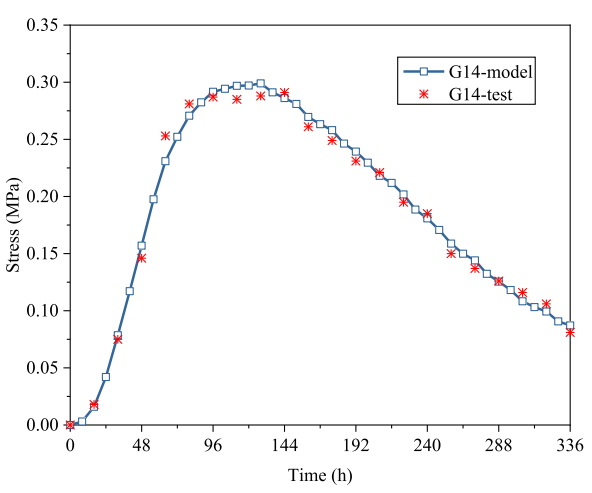

(b) G14

Fig. 13 Comparison between the predicted and measured stress along longitudinal direction

Figure 14 shows progression of the maximum principal tensile stress in the PC box girder at hydration age. For the PC box bridge girder without pipe-cooling system, the maximum principal tensile stress in the PC box bridge girder reaches the peak value of 1.73 $\mathrm{MPa}$, which occurs at $96 \mathrm{~h}$. Subsequently, the maximum principal tensile stress remained basically unchanged between 96 and $176 \mathrm{~h}$, and then decreases slowly. For the PC box bridge girder with pipe-cooling system, the maximum principal tensile stress increases more rapidly during cooling (between 0 and $48 \mathrm{~h}$ ) than that without pipe-cooling. During this period, the maximum principal tensile stress appears around pipe. After cooling, the principal tensile stress around pipe decreases rapidly, and position of the maximum principal tensile stress shifts from vicinity of pipe to other positions. Therefore, the maximum principal tensile stress has a sudden change between 48 and 56 h, as shown in Fig. 14 . Subsequently, the maximum principal tensile stress continues to increase due to the thermal gradient caused by hydration heat. As compared to the case without pipe-cooling, the peak value of maximum principal tensile stress can be reduced by about $0.22 \mathrm{MPa}$ using pipe-cooling. It can be concluded that pipe-cooling is an effective measure to improve the safety reserve of $\mathrm{PC}$ box bridge girders against cracking.

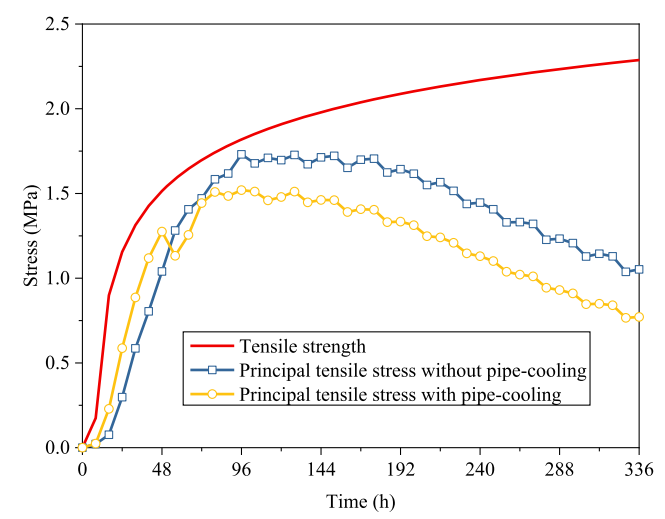

Comparison of maximum principal tensile stress in the PC box bridge girder with or without pipe-cooling system

Fig. 14 Comparison of maximum principal tensile stress in the PC box bridge girder with or without pipe-cooling system 


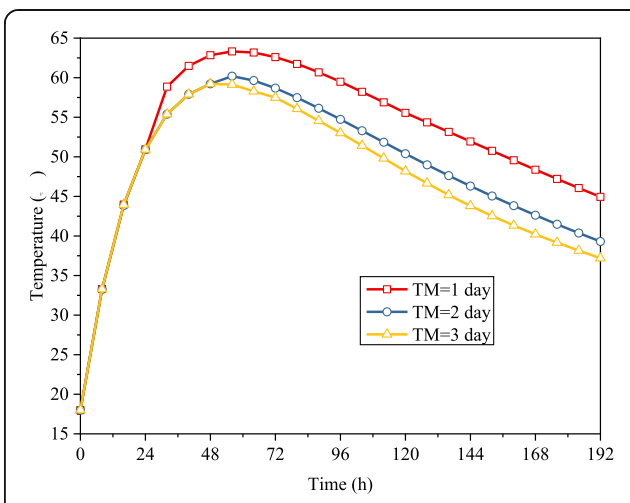

(a) Highest temperature

Progression of temperature and stress in the PC box bridge girder with different cooling time

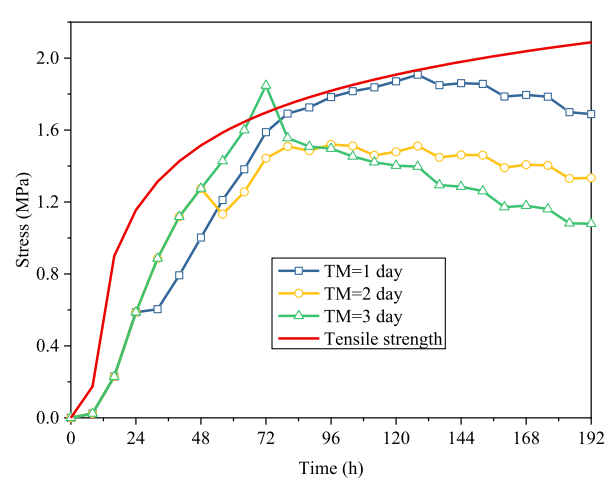

(b) Maximum principal tensile stress

Fig. 15 Progression of temperature and stress in the PC box bridge girder with different cooling time

\section{Parametric studies}

Progression of the highest temperature and maximum principal tensile stress are used to evaluate influence of different parameters, namely cooling time, cooling water flow rate, cooling water temperature and cooling period on thermal-mechanical behaviour of PC box bridge girders at early age of curing.

\subsection{Cooling time}

The cooling time (TM) is assumed to be 1 day, 2 days and 3 days, to evaluate effect of cooling time on thermal-mechanical behavior of the PC box bridge girder at hydration age. Figure 15 shows progression of the highest temperature and maximum principal tensile stress in the PC box bridge girder with different cooling time. It can be seen from Fig. 15(a) that the highest temperature can be reduced by prolong cooling time. However, extension of cooling time will reduce the cooling efficiency. The peak temperature decreases about $3{ }^{\circ} \mathrm{C}$ when the cooling time is extended from 1 day to 2 days, while the peak temperature decreases only about $1{ }^{\circ} \mathrm{C}$ when the cooling time is further extended by 1 day. Figure 15 (b) shows that the maximum principal tensile

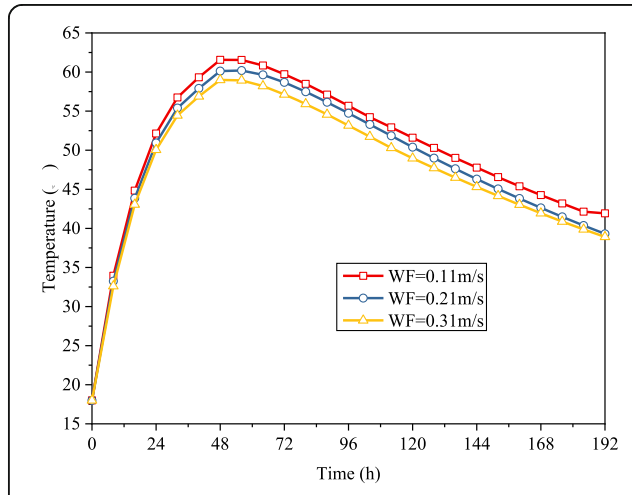

(a) Highest temperature (a) Maximum principal tensile stress
Progression of temperature and stress in the PC box bridge girder with different cooling water flow rate

Fig. 16 Progression of temperature and stress in the PC box bridge girder with different cooling water flow rate

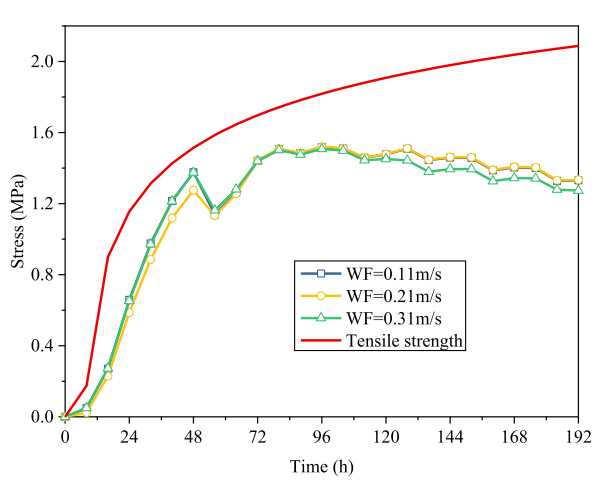

(b) Maximum principal tensile stress 
stress exceeds tensile strength when the cooling time is 3 days. This is mainly due to the fact that the temperature difference between cooling water and concrete increases as temperature of concrete increases, resulting in greater tensile stress in concrete around pipe. Therefore, the cooling time should be reasonably controlled to prevent the occurrence of cracking.

\subsection{Cooling water flow rate}

The cooling water flow rate (WF) is assumed to be $0.11 \mathrm{~m} / \mathrm{s}, 0.21 \mathrm{~m} / \mathrm{s}$ and $0.31 \mathrm{~m} / \mathrm{s}$. Figure 16 shows progression of the highest temperature and maximum principal tensile stress in the PC box bridge girder at hydration age with different cooling water flow rate. Figure 16(a) indicates that increasing the cooling water flow rate can reduce the highest temperature. The peak temperature decreases about $1^{\circ} \mathrm{C}$ when the water flow rate increases $0.1 \mathrm{~m} / \mathrm{s}$. The maximum principal stress can be effectively reduced when cooling water flow rate is $0.21 \mathrm{~m} / \mathrm{s}$, as shown in Fig. 16(b). However, accelerating or decelerating cooling water flow rate will lead to an increase in principal tensile stress. This can be attributed to the fact that the maximum temperature cannot be effectively reduced when cooling water flow rate is slow, whereas the temperature around pipe is relatively low. Although faster cooling water flow rate effectively reduces the maximum temperature, the temperature of concrete in the vicinity of pipe approximately equal to cooling water temperature due to sufficient heat transfer. These will increase the temperature difference between pipe and concrete, thus generating large tensile stress around pipe.

\subsection{Cooling water temperature}

Progression of the highest temperature and maximum principal tensile stress in the PC box bridge girder at hydration age with different cooling water temperature (WT), namely $12{ }^{\circ} \mathrm{C}, 15^{\circ} \mathrm{C}$ and $18{ }^{\circ} \mathrm{C}$ is shown in Fig. 17 . The highest temperature can be reduced by decrease of cooling water temperature. The cooling effect is more obvious with the difference between cooling water temperature and initial casting temperature increasing. However, reducing temperature of cooling water will increase the thermal

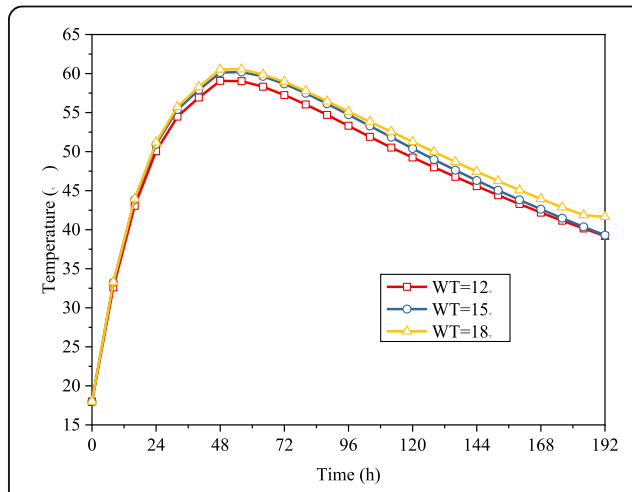

(a) Highest temperature Progression of temperature and

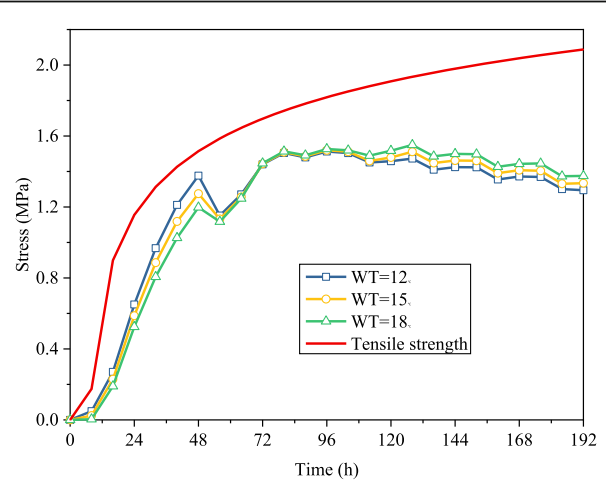

(b) Maximum principal tensile stress girder with different cooling water temperature

Fig. 17 Progression of temperature and stress in the PC box bridge girder with different cooling water temperature 
gradient between cooling water and concrete, resulting in an increase in the principal tensile stress around pipe, as shown in Fig. 17(b). Therefore, the cooling water temperature should be taken properly, so that the highest temperature and also the maximum principal tensile stress can be effectively reduced.

\subsection{Cooling period}

At present, some scholars have proposed a three-stage pipe-cooling method for mass concrete (Chen et al. 2011; Cheng et al. 2016). The purpose of the first stage is to reduce the peak temperature of concrete, the second stage aims to disperse temperature difference and reduce the consequent stress, and the last stage is to stabilize the temperature of concrete. The cooling period (PD) is assumed to be one-stage, twostage and three-stage. The one-stage cooling refers to continuous cooling within 2 days after pouring is completed, and the cooling water temperature is $15^{\circ} \mathrm{C}$. The two-stage cooling refers to cooling on the first and third day after pouring is completed, the cooling water temperature is $15^{\circ} \mathrm{C}$ and $35^{\circ} \mathrm{C}$, respectively. The three-stage cooling refers to cooling on the first, third and fifth day after pouring is completed. The cooling water temperature is $15^{\circ} \mathrm{C}, 35^{\circ} \mathrm{C}$ and $30^{\circ} \mathrm{C}$, respectively.

Figure 18 shows progression of the highest temperature and maximum principal tensile stress in the PC box bridge girder at hydration age with different cooling period. One-stage cooling has the best effect on reducing the highest temperature of concrete. Compared with multi-stage cooling, the highest temperature of the PC box bridge girder can be reduced by $2{ }^{\circ} \mathrm{C}$ using one-stage cooling. As shown in Fig. 18(b), the maximum principal tensile stress of the $\mathrm{PC}$ box bridge girder using one-stage cooling or two-stage cooling is much smaller than the tensile strength, while three-stage cooling has little effect on stress progression as compared with two-stage cooling. Generally, both one-stage and two-stage cooling can be used to mitigate the adverse effects of hydration heat in PC box bridge girders.

\section{Conclusions}

A numerical analysis method is used to delve into thermal mechanical behaviour of PC box bridge girders at hydration age and effects of different parameters of pipe-cooling

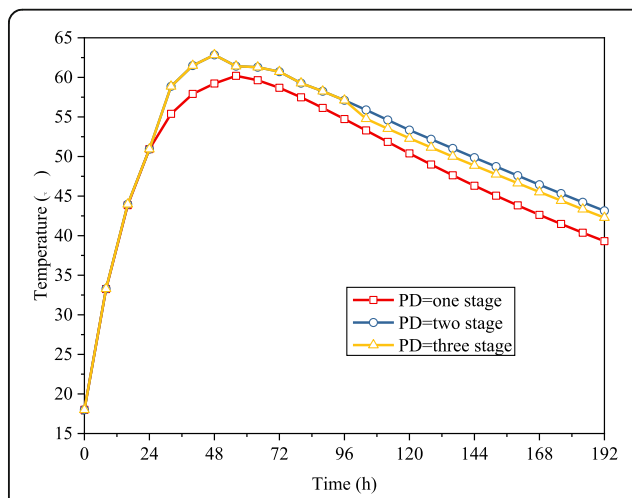

(a) Highest temperature Progression of temperature and stress in the PC box bridge girder with different cooling period

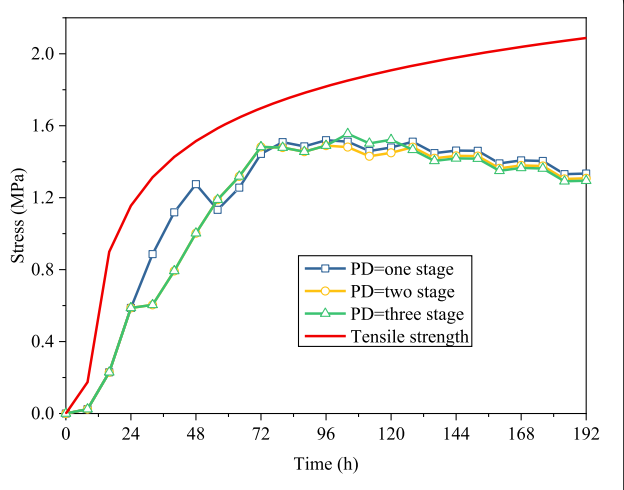

(b) Maximum principal tensile stress Fig. 18 Progression of temperature and stress in the PC box bridge girder with different cooling period 
on behaviour of PC box bridge girders during curing. The main conclusions from the numerical analysis can be drawn as below:

- The proposed inverse analysis method for adiabatic temperature rise function, and the thermo-hydro-mechanical model incorporating wind speed, ambient temperature and pipe-cooling system, is capable of predicting thermal mechanical behaviour of a PC box bridge girder on the pier top at hydration age.

- The temperature distribution of layered pouring PC box bridge girders has obvious layering phenomenon and the highest temperature appears at junction of bottom flange, web and diaphragm. The temperature of concrete at junction of top flange and web is lower due to large number of prestressed ducts.

- As compared to the case without pipe-cooling, the temperature and principal tensile stress can be significantly reduced using pipe-cooling in PC box bridge girders. However, the principal tensile stress generated in the vicinity of pipe increases more rapidly during cooling.

- Increasing cooling time, cooling water flow rate or decreasing cooling water temperature can reduce the highest temperature, whereas increase the principal tensile stress around pipe during cooling. So cooling time, cooling water flow rate and cooling water temperature should be taken reasonably to prevent cracking in PC box bridge girders.

- Both one-stage and two-stage cooling are effective measures to minimize the adverse effects of hydration heat in PC box bridge girders. Three-stage cooling is of little significance to prevent cracking of PC box bridge girders as compared with two-stage cooling.

Acknowledgments

Not applicable.

Authors' contributions

Wen developed thermo-hydro-mechanical model. Song wrote the initial draft of manuscript. Zhang G and Zhang YF supervised and reviewed all the versions of the manuscript. All authors read and approved the final manuscript.

\section{Funding}

The research described in this paper was financially supported by Natural Science Foundation of China (Grant No. 51878057), Research Fund for the Central Universities of China (Grant No. 300102210217) and Science and Technology Project of Transportation Department of Ningxia Hui Autonomous Region (nx20170161). Any opinions, findings, and conclusions or recommendations expressed in this paper are those of the authors and do not necessarily reflect the views of the sponsors.

Availability of data and materials

Not applicable.

Competing interests

The authors declare that they have no competing interests.

Received: 25 June 2020 Accepted: 9 August 2020

Published online: 02 September 2020

References

ANSYS (2018) ANSYS metaphysics (version 19.0). ANSYS Inc, Canonsburg

Chen SH, Su P, Shahrour I (2011) Composite element algorithm for the thermal analysis of mass concrete simulation of cooling pipes. Int J Numer Method H 21(3-4):434-447

Cheng J, Li TC, Liu XQ, Zhao LH (2016) A 3D discrete FEM iterative algorithm for solving the water pipe cooling problems of massive concrete structures. Int J Numer Anal Met 40(4):487-508

Davie CT, Pearce CJ, Bicanic N (2010) A fully generalised, coupled, multi-phase, hygro-thermo-mechanical model for concrete. Mater Struct 43(1):13-33

Ding JX, Chen SH (2013) Simulation and feedback analysis of the temperature field in massive concrete structures containing cooling pipes. Appl Therm Eng 61(2):554-562 
Kim SJ, Yang KH, Moon GD (2015) Hydration characteristics of low-heat cement substituted by fly ash and limestone powder. Materials 8(9):5847-5861

Kodur VKR, Bhatt PP, Soroushian P, Arablouei A (2016) Temperature and stress development in ultra-high performance concrete during curing. Constr Build Mater 122:63-71

Liu XH, Duan Y, Zhou W, Chang XL (2013) Modeling the piped water cooling of a concrete dam using the heat-fluid coupling method. J Eng Mech 133(9):1278-1289

Liu XH, Zhang C, Chang XL, Zhou W, Cheng YG, Duan Y (2015) Precise simulation analysis of the thermal field in mass concrete with a pipe water cooling system. Appl Therm Eng 78:449-459

Myers TG, Fowkes ND, Ballim Y (2009) Modeling the cooling of concrete by piped water. J Eng Mech 135(12):1375-1383

Sabbagh-Yazdi S, Amiri-Saadatabadi T, Wegian FM (2013) 2D linear Galerkin finite volume analysis of thermal stresses during sequential layer settings of mass concrete considering contact interface and variations of material properties part 1: thermal analysis. J S Afr Inst Civ Eng 55(1):94-103

Schackow A, Effting C, Gomes IR, Patruni IZ, Vicenzi F, Kramel C (2016) Temperature variation in concrete samples due to cement hydration. Appl Therm Eng 103:1362-1369

Singh PR, Rai DC (2018) Effect of piped water cooling on thermal stress in mass concrete at early ages. J Eng Mech 144(3): 04017183

Song CJ, Zhang G, Hou W, He SH (2020) Performance of prestressed concrete box bridge girders under hydrocarbon fire exposure. Adv Struct Eng 23(8):1521-1533.

Tahersima M, Tikalsky P (2017) Finite element modeling of hydration heat in a concrete slab-on-grade floor with limestone blended cement. Constr Build Mater 154:44-50

Wang D, Shi C, Wu Z, Xiao J, Huang Z, Fang Z (2015) A review on ultra high performance concrete: part II. Hydration, microstructure and properties. Constr Build Mater 96:368-377

Yang J, Hu Y, Zuo Z, Jin F, Li QB (2012) Thermal analysis of mass concrete embedded with double-layer staggered heterogeneous cooling water pipes. Appl Therm Eng 35:145-156

Zhang G, Zhu MC, He SH, Hou W (2017) Thermo-mechanical behavior of prestressed concrete box girder at hydration age. Comput Concr 20(5):529-537

Zhu BF (ed) (2013) Thermal stresses and temperature control of mass concrete. Butterworth-Heinemann, London

Zhu ZY, Qiang S, Chen WM (2013) A new method solving the temperature field of concrete around cooling pipes. Comput Concr 11(5):441-462

Zuo Z, Hu Y, Li QB, Liu GW (2015) An extended finite element method for pipe-embedded plane thermal analysis. Finite Elem Anal Des 102-103:52-64

Zuo Z, Hu Y, Li QB, Zhang LY (2014) Data mining of the thermal performance of cool-pipes in massive concrete via in situ monitoring. Math Probl Eng 985659

\section{Publisher's Note}

Springer Nature remains neutral with regard to jurisdictional claims in published maps and institutional affiliations.

\section{Submit your manuscript to a SpringerOpen ${ }^{\circ}$ journal and benefit from:}

- Convenient online submission

Rigorous peer review

- Open access: articles freely available online

High visibility within the field

- Retaining the copyright to your article

Submit your next manuscript at $\boldsymbol{\nabla}$ springeropen.com 